\title{
Digital Economy as A Highest Stage Development of Infocommunication Technologies
}

\author{
Ravshanbek Urunov , Tashkent Financial institute Republic of Uzbekistan \\ Abduazim Abdurakhmanov , Tashkent Financial institute Republic of Uzbekistan \\ Asal Jamaldinova, Tashkent Financial institute Republic of Uzbekistan \\ Nigora Shakirova , Tashkent Financial institute Republic of Uzbekistan
}

\begin{abstract}
The article examines the concept of "digital economy" and its relationship with information and communication technologies of the 21st century, from the standpoint of economic theory and practice of public administration. Also, the article reveals the implementation of the digital economy and using prospects in industry, public and social services, household management in the life. The content and structural composition of the digital economy, instrumental base and information content are detailed. The experience of advanced countries in using the achievements of the digital economy in industrial and social spheres of activity is analyzed.
\end{abstract}

Keywords: digital economy, information and communication technologies, digital company, ecosystem, social life, digitalization strategy.

$\begin{array}{lll}\text { Received: 05.12.2020 } & \text { Accepted: 10.01.2021 } & \text { Published: 07.02.2021 }\end{array}$

\section{INTRODUCTION}

The term "digital economy" has moved from scientific journalism to mass media relatively recently, in the last 5-6 years. But now this name has become used commonly, including in the field of public administration. To clarify the goals, objectives and content of the new direction in the development of the domestic economy, we will consider the essence of the basic concepts.

By the definition of the World Bank, in the most general sense, the digital economy is a system of economic, social and cultural relations based on the usage of digital information and communication technologies (ICT) [1]. In the scientific literature, at the moment there is not single definition of the concept of "digital economy". There are some examples, according to Gartner analysts, digital economy is creation, consumption and management of the value that associated with digital products, services and assets in organizations [10]. Consultants Boston Consulting Group believe that the digital economy is the usage of opportunities for online communication and innovative digital technologies for all participants in the economic system - from individuals to large companies and states [10]. Experts of The Organization for Economic Co-operation and Development (OECD) emphasize on trade: "the digital economy is markets based on digital technologies that facilitate the trade of goods and services through e-commerce" [10]. In our domestic conditions, the digital economy is the economic activity of the state, functioning which is ensured by automated control processes at all levels: from production to consumption[2].

The digital economy, in its broadest sense, simply means the use of information technology in production, management, communication and entertainment. From this point of view, and automation = digital economy, there is nothing new in "digitalization". Practice shows that now there is not a single branch of economic activity from agriculture to metallurgy, from medicine to housing and communal services, there is not complete without "computerization".

Historically, since the beginning of the 21st century, the emergence of the digital economy has led to the ubiquitous spread of broadband Internet access, the development of mobile technologies, high speed of information transfer, increasing telecommunication networks, introduction of digital signature. But not just that. we are talking about providing consumers with goods and services in electronic form, as well as about extensive automation of industry, agriculture and other spheres of the economy. Digitalization and globalization are inseparable. The fewer boundaries, the faster development, the digital economy will benefit those countries that form a single economic space. The digital economy only reflects the trends that we observe today: IT companies are overtaking commodity corporations in terms of market capitalization. So, the whole world is embraced by the idea of digital transformation. Services are easier to digitalize, and its influence is more noticeable in trade, the financial sector, public administration, and education. These are advantage points for business. The digital economy has many benefits. It reduces the cost of payments and opens new sources of income. In the online mode, the cost of services is lower than in the traditional economy (firstly, reducing the cost of promotion). 
Also, goods and services in digital world can quickly go global market, become available to people in any point of the world. The proposed product can be almost instantly modified to meet new expectations or needs of consumer. The digital economy provides much more diverse content to consumers: informational, educational, scientific, entertainment. An important component of digitalization is ensuring information security of innovative technologies that ensure public confidence in the digital economy. The backbone of the digital economy, its foundation is a grassroots economic link-digital company that seeks to move most of the business processes with online. The online management, control and analysis of all main business processes of the company: negotiation of contracts, accounting, logistics processes, registration of transactions, purchases, personnel training, monitoring of relationships with partners and clients, technical support for solutions, etc.

In addition to information systems, it is necessary to introduce an appropriate "digital" culture in the company. This complex makes the company "digital", ensures its efficiency, productivity, business growth potential, then there are competitive points.

\section{LITERATURE REVIEW}

The concept of the "digital economy" is originated in the last decade of the 20th century. The introduction of this phrase, using this term in 1995 by Nicholas Negroponte from the University of Massachusetts. Over the past period in the scientific environment, there are many approaches to the disclosure of the term "digital economy".

So, M.L. Kaluzhsky defines the digital economy as the communication environment of economic activity on the Internet, as well as forms, methods, tools and results of its implementation [7]. The Digital Economy Outlook (OECD) regards this concept as a general term for describing markets that are focused on digital technologies and include, as a rule, trade in information goods and services through ecommerce [6]. In this case, digital technologies mean the Internet, mobile phones and all other means of collection, storage, analysis of information and exchange in digital form [1].

Thomas Mesenburg identified three main components of the digital economy [8]:

- e-business infrastructure (technical means, software products, telecommunications, networks, human capital, etc.);

- $\quad$ e-business (a way of doing business, any process is implemented by the organization with using information and communication networks);

- $\quad$ e-commerce (transfer of goods, for example, the on-line sale, on-line booking).

According to V. Katasonov, in the most general form, the digital economy can be present as the part of economic relations that is mediated Internet, cellular communication, ICT [9]. Digital technologies in modern the world create fundamentally new opportunities for building interaction between the state, business and the population, excluding long chains of intermediaries and speeding up various transactions and operations. For successful functioning business, in the digital economy there is not three elements or composite elements are passed by parts of infrastructure.

Based on this understanding of the digital economy, the authors in the many studies come to the conclusion that this model of the economy will provide "digital dividends" to society in the form of increasing access to markets and market coverage, growing domestic and market efficiency, including higher labor productivity, reducing transaction costs, employment growth (unemployment reduction), full satisfaction of human needs, productivity of working hours, poverty reduction and even weakening (or completely overcoming) the social polarization of society $[1,10,12]$.

\section{RESEARCH METHODOLOGY}

The main content of the functioning of the digital economy is a global network of economic and social activities that implemented through such platforms like the Internet, mobile and sensor networks. Digital economy tools - information and communication technologies (ICT), whose composition can be seen in Table 1. In 2017, the volume of sales in the global ICT market is valued at 4 trillion U.S dollars [10].

Table 1

Sales volumes in the global ICT market in 2017, billions of dollars

\begin{tabular}{|l|l|c|}
\hline 1. & Computer equipment & 368.7 \\
\hline 2. & Telecommunication services & 608.1 \\
\hline 3. & Software & 634.2 \\
\hline 4. & $\begin{array}{l}\text { Technical outsourcing and } \\
\text { hardware maintenance }\end{array}$ & 475.8 \\
\hline 5. & Telecommunication equipment & 331.8 \\
\hline 6. & $\begin{array}{l}\text { Technical consulting and services } \\
\text { system integration }\end{array}$ & 573.3 \\
\hline
\end{tabular}


For the successful functioning of the business, three elements or components are required in the digital economy parts: infrastructure (Internet access, software, telecommunications), e-business (conducting business through computer networks), e-commerce (trade, distribution of goods through the Internet). We can say that they are electronic business technologies, internal driving forces. But the development of the digital economy directly depends from the introduction of such "external", are advanced science-intensive technologies as nanotechnology, biotechnology, technology of energy systems, quantum technologies, etc. Conversely, further development of ICT, including: cloud computing technologies, processing technologies, big data, mobile technologies, internet, technologies, geo-location technologies, technologies of distributed communication networks, gives impetus, the development of high technologies in the real "traditional" economy. Let us explain these new concepts.

CLOUD TECHNOLOGIES CALCULATION - provision of services: resource and infrastructure; the application development platforms; using the software for specific customer requests. The development of cloud services in the EU is determined by the strategy of the EU Digital Single Market, that is, the "European cloud", which should unite all digitized information and store in European databases for the purpose of ensuring access to it for all interested parties. Cloud creation secured by public and private investments, which are estimated at 6.7 billion Euros over 5 years.

TECHNOLOGIES OF LARGE DATA is not a very accurate name, it is used to indicate ways for processing "hypervolumes" of information, the characteristic of the digital economy. The expected growth in the digital economy volumes of digitized information, development of cloud technologies, requires the availability of modern Data Processing Centers (DPC), providing reliable storage of big data and the implementation of various clouds, including public, hybrid and private [2].

Data center is a key component of a unified technological infrastructure of e-government [9].

MOBILE TECHNOLOGIES - a segment of the digital economy based on the creation of cellular networks, meeting the needs of the cloud calculations for indicators such as data transfer rate, traffic volume, client network capacity, power consumption. In Uzbekistan, mobile technologies are implemented by telecom operators, they allow you to collect and process information (in a single data center), both for managing household appliances and for managing individual production facilities and entire enterprises. As a tool base, the Internet things can use, adapt or universal software and hardware complexes: for the automation of production processes in industry, agricultural production, telecommunications, household sphere of households [10].

E-LOCATION TECHNOLOGIES have opened up new opportunities for the provision of information services, with taking into account the location of the client (user), for example, satellite tracking services for transport and people: GPS, GLONASS. Using business application satellite tracking makes it possible to determine deviations from routes, unauthorized stops, misuse of transport, control of fuel consumption, etc. High precision autographic software products are used to

indoor use: airports, stadiums, train stations, etc. [2].

THE DISTRIBUTION TECHNOLOGIES, THE COMMUNICATION NETWORKS - the basis of the business model of the data center operation: the expansion of capacity and the creation of mega-data centers, are united in the distributed network that connected by channels with a large bandwidth. Due to economies of scale, maximum reliability is ensured, information safety, fault tolerance, high standards of service agreements and attractive cost of services.

ECOSYSTEM - unites Data centers, backbone network infrastructure, traffic exchange points, own import-independent cloud new platform [9]. The infrastructure digital economy - the elements of external digitalization cookies: managerial, legislative and regulatory acts, supplying organizations: energy sky, communication, educational points, housing and communal services enterprises, etc.

The efficiency of the transition to digital economy is determined by the available and the ability to use tools, formation that created in one sphere for the life of people, in others spheres and industries. With this mind, the key, necessary condition is to provide compatibility of the elements of its ECOSYSTEM: the implementation platforms and services, applications, elements of electrical networks communication, software applications, provision. The solution to this problem is the result of the wellcoordinated work of the entire IN- FRASTRUCTURES of the digital economy, the creation and the function of the state.

The digital economy is underdeveloped not only digitalization, but also society, business and government, therefore, its development consists in accelerating processes of penetration of digital relations at all levels of interaction, its participants - from state to personal. 


\section{ANALYSIS AND RESULT}

There is a rapid development in digital technology in the past decade. The population with accessing to the Internet increased between 2005 and 2016 from 1 to 3.4 billion people, while covering more than $40 \%$ of the total population of the planet [13]. The number of households in developing countries, those who have a mobile phone are higher than those who have access to electricity or clean drinking water Almost $70 \%$ of those in the bottom quintile of the population own mobile phones, while in high-income countries this figure is $98 \%$ [1].

Digitalization is changing the face and structure of the economy, breaking the usual business models, leading to the expansion of markets and opportunities, increasing competition and growing competitiveness, and both among individual business entities and entire countries. A striking example of this is the data provided in the Report.

McKinsey Global Institute, according to which, after 20 years of growth (from 1987 to 2007), the share of traditional flows of goods, services and finance in global GDP fell from 53\% in 2007 to 39\% in 2014, while the volume of cross-border data exchange in the period from 2005 to 2014 increased 45 times. In 2014, about $12 \%$ of world merchandise trade was carried out through international e-commerce, about $50 \%$ of world trade in services is already digitalized. That is why many experts agree that digital transformation is becoming one of the key drivers of global economic growth. So, according to one of the authoritative experts in the field of digital economy, The Boston Consulting Group (BCG), the share of the digital economy in the developed countries has grown since 2010 by 1.2 percentage points. In developing countries, this indicator increased from 3.6 to $4.9 \%$ (Table 2).

\section{Table 2}

Growth dynamics of the share of the digital economy in the different countries, G20,\%

\begin{tabular}{|l|l|l|}
\hline Country & $\mathbf{2 0 1 0}$ & $\mathbf{2 0 1 6}$ \\
\hline Great Britain & 8.3 & 12.4 \\
\hline The South Korea & 7.3 & 8 \\
\hline China & 5.5 & 6.9 \\
\hline European Union & 3.8 & 5.7 \\
\hline India & 4.1 & 5.6 \\
\hline Japan 4.7 5.6 & 4.7 & 5.6 \\
\hline USA & 4.7 & 5.4 \\
\hline Mexico & 2.5 & 4.2 \\
\hline Saudi Arabia & 2.2 & 3.8 \\
\hline Australia & 3.3 & 3.7 \\
\hline Canada & 3 & 3.6 \\
\hline Argentina & 2.9 & 3.3 \\
\hline Russia & 1.9 & 2.8 \\
\hline South Africa & 2.2 & 2.5 \\
\hline Brazil & & \\
\hline
\end{tabular}


The high level of development of e-commerce in China is noteworthy. According to the same BCG company, in 2011 the turnover of e-commerce in the PRC was amounted to 18 billion US dollars, and at the end of 2016. Chinese consumers spent on purchases through the Internet is in the order of 750 billion US dollars, which is more than the figures for the United States and Great Britain combined. In general, according to the Ministry of Commerce of the PRC, the share of China in international e-commerce by the end of 2016 was $39.2 \%$ [15]. At the same time, according to the sectoral development program adopted in the country for 2016-2020, the volume e-commerce will grow in 5 years to 5.8 trillion. US dollars [16].

According to estimates of the McKinsey Global Institute [17], by 2025, digital technologies will drive China's GDP growth up to $22 \%$, and Russia - up to 34\%. The expected Value added by Digital Technologies in the United States by 2025 may amount to 1.6-2.2 trillion US dollars. These economic forecasts are predetermined not only by a high level of automation of existing processes, but also by the introduction of fundamentally new, breakthrough business models and technologies. Among them, digital platforms, digital ecosystems, in-depth analytics of big data, Industry 4.0 technologies (3D printing, robotization, Internet). According to the McKinsey Global Institute [17], the annual investment in the global economy of the Internet of Things will be from 4 to 11 trillion US dollars until 2025. Another trend in e-commerce is the increasing activity and role of small and medium-sized businesses in global trade.

Digitalization has allowed the most active and entrepreneurial representatives of small and mediumsized businesses to transform into "micro-multinational" organizations, including by providing them accessing to the infrastructure of digital platforms that operate on the so-called "'onnect and play" principle; and unprecedented access to the platform's built-in global customer base.

The most extensive databases of potential customers are contained in social media platforms. So, according to the calculations of the company Facebook [18], only for 2013-2017. the number of small and medium-sized businesses are registered on its platform increased by more than 2.5 times. The share of their foreign subscribers is about 30\%. This fact characterizes social media platforms as a powerful marketing tool, especially for companies interested in exporting growth, indicators.

Meanwhile, e-commerce is an important for the component of the digital economy. In some countries, for example, electronic banking is relatively well developed. BCG specialists [14] in 2016 made an attempt to assess the level of development of digital economy, taking into account all its sectors. They expressed the results in indices that take into account many parameters ("BCG indices"). All countries were ranked in descending order of the BCG indices. Among the leaders

turned out to be: Denmark (1); Luxembourg (2); Sweden (3); South Korea (4); Netherlands (5); Norway (6); Great Britain (7). The lower levels of the rating were taken by the UAE (30); China (35); Russia (39); India (80th).

BCG specialists divide the diverse digital economies into 5 groups. The grouping criteria were the relative level of development of digital transactions and GDP per capita. BCG experts classify the countries with the highest percentage of "digitization" of economic transactions and the highest level of technologies that used for such "digitization" to the group of leaders. These are: South Korea, Denmark, Great Britain, Sweden, Norway and the Netherlands.

The second (main) group includes most of the countries with developed economies, in particular, Germany, the USA, Japan, and the countries of the European Union.

The third group covers countries with a high level of prosperity (GDP per capita), but with relatively lower rates of "digitization" of operations. These are the countries of the Middle East, primarily the UAE and Saudi Arabia. BCG experts emphasize that the number of countries of the third group, there are themes of the development of digital operations, which is why in the future they can rise to the second or even the first group.

The fourth group is represented by "emerging leaders". In these countries, the level of development of digital operations is higher than the level of development of the economy. The most prominent representative of this group is China. All other countries are classified by BCG experts as lagging behind in the development of the digital economy.

In Uzbekistan, since the establishment of independence, special attention has been paid to the intensive development of information and communication technologies. The country is implementing large-scale digital infrastructure projects, including the development of public electronic services, the expansion of the electronic procurement system, the involvement of citizens in the process of making socially significant decisions.

According to Internet Live Stats [19], in the terms of the number of Internet users, our country is currently ranked the first place in Central Asia, and the $37^{\text {th }}$ place in Asia. As of 2016, the speed of access to international information networks reached almost $35 \mathrm{Gbps}$ (at the end of 2015 - $26.4 \mathrm{Gbps}$ ), mobile communication covers $92 \%$ of the republic's settlements, the number of subscribers was 20.8 million people. At the same time, according to the Program for the Development of the Service Sector for 2016- 
2020, based on the active trend of growth in the number of users mobile communications, by 2020 this indicator is projected to reach 27 million people [20].

Nevertheless, despite the positive dynamics in development information technologies and communications, require their solution to the problem of their more active implementation in the economy. The rapid development in the world of digital technologies and the expansion of their role in the global economy, on the one hand, open up new opportunities and horizons for further development, and on the other hand, they give rise to serious challenges and threats for countries and companies that have not learned to live in a dynamic world of permanent innovation.

\section{CONCLUSION AND RECOMMENDATION}

One of the key trends in the global economy over the past decades is its rapid digitalization. Digital transformation is changing shape and structure of economies, breaking the usual business models, lead to the expansion of markets and opportunities, become the most important engine of world economic growth.

The results of the analysis allow us to believe that with the high degree of probability in the near future, the level of digitalization will determine the competitiveness of not only business, but also entire countries. At the same time, only those countries and companies can adapt most quickly and maximize the benefits of these changes.

To adopt successfully to change and reduce technological gap with the leading players, Uzbekistan needs to develop effective responses to the challenges of the digital age. In particular, the development of long-term evidence-based strategies is required. In this context, the outstripping pace of development should imply the gradual "catch-up" introduction of technologies of the previous generation. This approach will not only place the country and business in the position of perpetually lagging behind, but also lead to significant risks, since players with fundamentally new business models may enter the market. For advanced development, it is important to identify trends in the field of digital technologies that the most affect the appearance and structure of the economy as a whole and on individual industries, in particular, and also determine which of them will allow the greatest benefits over the next 5-10 years.

According to the Decree, the President of the Republic of Uzbekistan dated June 30, 2017 №UP-5099, today the necessary favorable conditions have been created in the country for this purpose. The development of sectoral programs for the modernization of the country's industry on the basis of the principles of "Industry 4.0" with the introduction of financial and non-financial mechanisms to stimulate demanding from enterprises for technologies. At the same time, it is important to motivate industrial enterprises to attract specifically domestic suppliers, engineering companies and research centers for the development and implementation of these technologies.

Thus, the digital economy is a powerful innovation, growth and social well-being and its development in Uzbekistan is a requirement of the modern era. Deepening and expanding digitalization will increase the competitiveness of domestic economy in the world arena, to provide conditions for a gradual transition to the level of innovation economy and knowledge economy, as well as increasing the quality and standard of living of the population.

\section{REFERENCES}

1. Word Bank. World Development Report 2016: Digital Dividends / Word Bank Group, 2016.

2. Tsvetkov V.A. Implementation of New Industrialization Strategies Economics // Bulletin of the Financial University, 2016. - T. 20. - №6 (96). -P. 19-30.

3. Kovalchuk Yu.A., Ishchenko M.M. High-tech production as a "new window of opportunity" in the post-crisis economy // Corporate management and innovative development of the economy of the North: Bulletin of the Research Center for Corporate Law, Management and Venture Capital investment of the Syktyvkar State University, 2016. - №3. -P. 25-33.

4. Electronic economy // Wikipedia [2016-2016] [Electronic resource]. - Access mode: http://ru.wikipedia.org/?oldid=81412399 (dateaccess: 07/18/2016).

5. The Speech by Shavkat Mirziyoyev at the ceremony inauguration of the President of the Republic of Uzbekistan on a joint meeting of the chambers of the Oliy Majlis [Electronic resource]. - Access mode: http://www.press-service.uz/ru/lists/view/111 (date accessed: 13.08.2017).

6. OECD. OECD Digital Economy Outlook 2012 / OECD Publishing, 2012.

7. Kaluzhsky M.L. Ecommerce Marketing Networks: institutional approach. - M .; Berlin: Direct-Media, 2014. - p. 402.

8. Mesenbourg. T.L. Measuring of the Digital Economy // The Netcentric Economy Symposium. University of Maryland, 2001. 
9. "IQTISODIYOT VA INNOVATIV TEXNOLOGIYALAR" ilmiy electronic journals. №5, SeptemberOctober, 2017 № 5, 2017 www.iqtisodiyot.uz

10. Katasonov V. Digital economy - the bright future of mankind or the stock market bubble? [Electronic resource]. - Access mode: http://www.kramola.info/vesti/novosti/cifrovaya-ekonomika-svetloe budushcheechelovechestva-ili-birzhevoy-puzyr (date accessed: 13.08.2017).

11. UNCTAD. Information Economy Report. 2015 / UN, Geneva, 2015.

12. OECD. OECD Digital Economy Outlook. 2015 / OECD Publishing, 2015.

13. GRIMES S. How well are Europe's Rural Businesses Connected to the Digital Economy? / European Planning Studies. Vol. 13. 2005. № 7. October.

14. Meeker M. Internet trends. 2017 // Code Conference materials. California, 2017.

15. Bank B. et al. Russia online? Catch up can not be left behind / Boston Consulting Group, 2016.

16. The share of China in e-commerce - 40\% // [Electronic resource]. - Access mode: https://hightech.fm/2017/05/31/china-ecommerce (date access: 08/29/2017).

17. Chinese authorities plan to increase the volume of e-commerce to $\$ 6$ trillion // [Electronic resource]. - Access mode: http://www.rosbalt.ru/business/2016/12/30/1580499.html (access date: $08 / 29 / 2017)$.

18. McKinsey Global Institute. The Internet of Things: Mapping the Value Beyond the Hype / McKinsey \& Company, 2015.

19. [Electronic resource]. - Access mode: https://www.facebook.com/business/news/helping-smallbusinesses-succeed-in-amobile-world\# / (date accessed: 29.08.2017).

20. Internet Users by Country // InternetLiveStats.2016 / [Electronic resource]. - Access mode: http://www.internetlivestats.com/internet-users-bycountry/ (date of access: 18.08.2017).

21. The number of Internet users has exceeded 13 million // [Electronic resource]. - Access mode: https://www.gazeta.uz/ru/2016/09/20/subscribers/ (date of access: 18.08.2017).

22. The Director of the Center "Electronic Government" of Uzbekistan on the results and the coming changes // DIGITAL REPORT [Electronic resource]. - Mode Access: https://digital.report/rukovoditel-elektronnogo-pravitelstva-uzbekistana-obitogah-i-gryadushhihperemenah/ (date of access: 25.08.2017). 